\title{
Toxic Effects of Sexual Drug Overdose: Sildenafil (Viagra)
}

\author{
Rohit Kumar Verma ${ }^{1}$, Mahipal Singh Sankhla ${ }^{2 *}$, Rajeev Kumar ${ }^{3}$ \\ ${ }^{I}$ Student of B.Sc. (Hons.) Forensic Science, Galgotias University, Greater Noida \\ ${ }^{2}$ Research Scholar, Division of Forensic Science, Galgotias University, Greater Noida \\ ${ }^{3}$ Associate professor, Division of Forensic science, Galgotias University, Greater Noida
}

*Corresponding Author: Mahipal Singh Sankhla, Research Scholar, Division of Forensic Science, Galgotias University, Greater Noida, India. Email: mahipal4n6@gmail.com

\begin{abstract}
In today's world main problem adolescence consumption of drugs are increasing day by day. Sildenafil is the sexual drug. Sildenafil is the drug which to increase sexual power and improves flow of blood to the phallus (male reproductive part). It's most commonly found in the form of brand names are Viagra and Revatio. It can be administrated orally or injected directly into the veins. Sildenafil is an effective inhibitor of recurring guanosine monophosphate in the corpus cavernosum and consequently rises the penile reaction to sexual stimulus. Sildenafil also causes some side effect like headache, heartburn, flushed skin, visual disturbance, and dyspepsia. Sildenafil does not protect with sexually transmitted diseases like HIV, hepatitis B, AIDS etc. Sildenafil may effect severe organ like cardiovascular system, reproductive system, pulmonary hypertension, retinal dysfunction etc. Due to overdose of the sildenafil the person get heart attack, stroke, irregular heartbeats and death may also occur in rare cases. This paper aims about the detailed study of the sexual drug and the poisonous effects which is caused to the humans.
\end{abstract}

Keywords: sildenafil, sexual drug, Viagra, dyspepsia.

\section{INTRODUCTION}

Sildenafil is the sexual drug. Sildenafil is a new oral drug specially aimed at the cure of erectile dysfunction [1]. Sildenafil citrate is a discerning inhibitor of phosphodiesterase 5 (PDE5) and stayed the initial agent through this way of act for the cure of man erectile dysfunction [2]. Male erectile dysfunction (ED) is the determined or recurring incapability to reach, or to uphold till end of the sexual action, a suitable erection [3]. Sildenafil (Viagra) conventional Food and Drug Administration approval in March 1998 such as the earliest oral agent for erectile dysfunction [4]. Sildenafil workings such as a modest inhibitor of an enzyme of the phosphodiesterase type five class (PDE-5). Here are eleven forms of phosphodiesterase found over the body [5, 6]. Sildenafil is a weak vasodilator, resultant in lesser, transitory decreases in systolic $(10 \mathrm{mmHg})$ and diastolic $(7$ $\mathrm{mmHg}$ ) blood pressure (BP) when directed orally; no clinically important special effects on heart rate (HR) have been stated [7]. Sildenafil is quickly engrossed, by maximum plasma concentrations happening in one hour after oral admin then a mean fatal half-life of three to five hours [5]. Since the approval of sildenafil, several information of unexpected death amid patients preserved by this drug have upraised about worries concerning its care in patients with coronary artery disease [8].

The furthermost usually stated adverse effects of sildenafil are headache, gastroesophageal reflux, dyspepsia, facial flushing, nasal congestion, pupil sparing, and third nerve palsy $[9,10]$. Described cardiovascular side properties in the usual healthy population are naturally slight and related with vasodilatation (ie, headache, flushing, and small decreases in systolic and diastolic blood pressures). However, although their incidence is small, serious cardiovascular events, including significant hypotension, can occur in certain populations at risk [11]. The blood pressure dropping effect of sildenafil is uncertain and therefore improbable to activate a reflex heart rate response. Certainly, a mild sympathetic reaction straight to the vasculature might remain accountable for the upkeep of blood pressure deprived of activating a impulse tachycardia [12]. Though, with pharmacological efforts resultant in larger reduction of blood pressure as understood by the nitrate contact study here is a minor impulse reaction in heart rate in demand toward uphold blood pressure 
[13]. The cardiovascular effects of sildenafil are important subsequently of the recurring incidence of vital cardiac disease in men with erectile dysfunction and information representing severe cardiac actions temporally related by the usage of this drug [14]. Sildenafil may be expectable to improve reduction of the cavernosal smooth muscle, which in go increases blood flow into the cavernosal spaces, thus foremost to increased intracavernosal pressure, a main issue in making an erect penis $[15,16]$. Sildenafil has remained carefully used in the action of erectile dysfunction of numerous etiologies through decent acceptance and a low occurrence of lateral special effects. Though, the statement that maximum issued information to age have been industry supported has presented a possible prejudice. In accumulation, insufficient studies to era devise inspected the side-effect outline of sildenafil in a medical exercise surrounding a widespread variety of patients. This description delivers a nonindustry maintained review in a campus condition of the side-effect outline of a general and widely used medicine $[17,18,19]$.

\section{Chemical Structure of Sildenafil Citrate}

Sildenafil is chemically 5-[2-ethoxy 5-(4-me thy lpip e razi ne-1-yl suI fony 1) phenyl) -1methyl-3-propyl-6, 7-dihydro1- H-pyrazolol [43-d] pyrimidin-7-one. With molecular formula $\mathrm{C}_{22} \mathrm{H}_{30} \mathrm{~N}_{6} \mathrm{O}_{4} \mathrm{~S}$ as shown in fig [20].

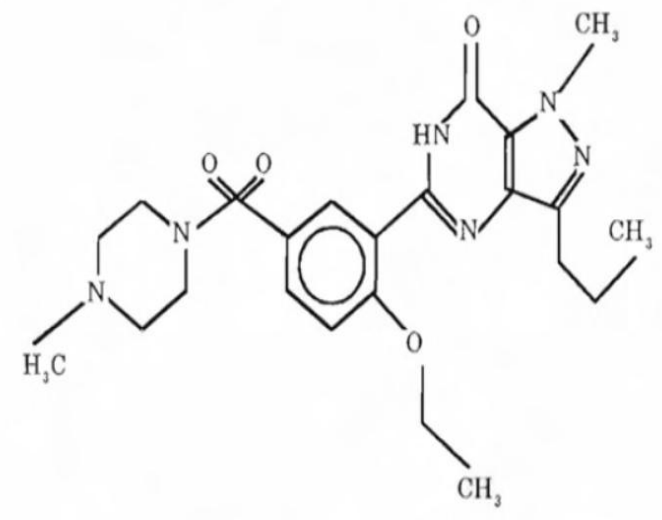

Fig: Chemical structure of sildenafil citrate [20]

\subsection{Sildenafil uses as a Club or Party Drug}

In the face of an increasing body of literature ,there are still no clear and reliable definitions or drug lists amongst educations; others have renowned this irregularity [21,22] and have mentioned to the term "club drug" as "amorphous" [23] Club drugs are frequently consumed at subversive all-night events known as "raves" [24]. Some men, therefore, may consume sildenafil to produce an erection to permit penetrating anal sex. Consequently, opposing effects since club drugs used in tour gathering surroundings might rise from overdose, medication interface, or leisure drugpharmaceutical interfaces. Furthermore, an inability to acquisition drugs might lead to changed sexual actions and increase the danger of HIV transmission [25-28]. Though club drugs are frequently used unaccompanied to excess, two additional mechanisms combine, maybe synergistically, to produce club drug poisonousness [29].

\subsection{Pharmacology of Sildenafil Citrate}

In scientific studies, sildenafil has been evaluated for its effect on the capability of men was varied in the residual $18 \%$ of men [30]. Sildenafil is quickly engrossed afterward oral administration, with absolute bioavailability of about $40 \%$. Its pharmacokinetics is dosage proportional above the suggested dosage range $(25,50$ and $100 \mathrm{gm})$. It is eradicated mainly by hepatic metabolism (mainly cytochrome P450 $3 \mathrm{~A} 4)$ and is rehabilitated to lively metabolite with properties alike to parental molecule sildenafil [20]. The pharmacodynamics close opinions that have remained examined with sildenafil imitate the dispersal of PDE5 in altered tissues, i.e., human corpus cavernosum (penile tumescence), vascular smooth muscle (vasodilatation), and platelets (antiplatelet function) [31]. Plasma absorptions highest in 30 to 120 minutes (median, 60 minutes) of oral dosage active in the desisted state. Sildenafil is chiefly absorbed by the cytochrome P450 3A4 (major route) and 2C9 (minor route) hepatic microsomal isoenzymes, which alteration it to an active $\mathrm{N}$-dimethyl metabolite that has continued exposed to individual $50 \%$ of the parent drug's potency for inhibiting PDE5. Plasma concentrations of this metabolite are $40 \%$ of individuals understood for sildenafil, so that the metabolite accounts for '20\% of the pharmacological effects of sildenafil [32].

\subsection{Adverse Effect of Sildenafil Citrate on Human Health}

\subsubsection{Effect of Hormonal and Reproductive Disturbance}

Brain controls hormonal secretion and it is sensitive to hormonal response; the neuro endocrine response system contains hypothalamus, pituitary, gonads, however also the amygdala that is related to the hypothalamic-pituitary axis (HPA) elaborate in 
the regulation, making and secretion of sex hormones [33]. Severe stimulus of testosterone secretion with management of human chorionic gonadotropin (HCG), a complex through luteinizing hormone-like activities, produces only a reduced reaction in uremic men [34].

\subsubsection{Effect of Retinal Dysfunction}

Though the part of sildenafil in erectile dysfunction exists well understood and has be clear in feature, optical effect of sildenafil are still deficient. There are about reports in the literature on the retinal side-effects of sildenafi1 $[35,36]$. Supervision of PDE5 inhibitors has been connected with visual turbulences such as blue tinge, increased glare of coloured lights and blurry vision; but, the precise device of these disorders takes not remained definitively clarified [37]. The PDE5 enzyme presented a extensive appearance on retinal and choroidal vessels, confirming the straight influence of PDE5 inhibitors on their enlargement. Lastly, surprisingly, we establish the occurrence of the PDE5 enzyme on ganglion (III neuron) and bipolar cell layers (II neuron). Ganglion and bipolar cell layers performs as a filter in the visual signal, giving a first codification of the neural signal [38-41].

\subsubsection{Effect on Pulmonary Hypertension in Human Health}

Pulmonary hypertension $(\mathrm{PH})$ of unidentified etiology or related with connective tissue syndrome is a lethal disease with few medical treatments [42]. Patients with liver diseases are at hazard of emerging pulmonary vascular complications [43]. Sildenafil has also been reported to increase arterial $\mathrm{Po} 2$ [44] and recover bodily performance in numerous circumstances of severe pulmonary hypertension, but no education has explored the consequence of a numerous daytime action by sildenafil on these variables in usual focusses bare to elevation circumstances [45, 46, 47]. Approximately medical doctor have initiated by sildenafil as another to, and in mixture with, in the initial organisation of $\mathrm{PAH}$, but its residence is inaccurate [48]. Headache existence a probable adversative outcome of sildenafil, though, its likely upsurge in preserved issues might have risk a likely helpful outcome on general AMS score since of a improved blood oxygenation. The suggestion of sildenafil in the action of HAPE has not stayed addressed in the current study since nobody of the issues agonised after this severe disorder. The valued effect on Ppa powerfully advises, though, that this drug could be extremely effective in this disorder, deprived of adverse systemic effect, opposing to the typically proposed calcium blockers $[49,50]$. A few uncontrolled clinical studies have suggested that combinations of aerosolised iloprost and sildenafil, as fine as aerosolised iloprost and are harmless and effective in selected patients with liberal disease in spite of prostanoid cure [51,52]. Preclinical studies have revealed that sildenafil selectively decreases pulmonary artery pressure with slight effect on systemic BP. Randomised, double blind, crossover design studies support these findings; sildenafil improved 6-min walking distance and reduced mean pulmonary arterial systolic pressure in patients with primary pulmonary hypertension $[53,54]$.

\subsubsection{Effect on Cardiovascular System}

Males through cardiovascular illness are further possible to have erectile dysfunction than the overall male inhabitants since together circumstances share a number of hazard influences [55]. Different cAMP-specific PDE-3 inhibitors (milrinone, vesnarinone, and enoximone) that rise long-standing death in patients with heart failure $[19,20]$, sildenafil stays extremely selective (4000-fold) for human PDE-5 over human PDE-3 and has not been found to elevate cAMP [56]. Anecdotal information of cardiovascular deaths associated with sildenafil use produced substantial worry in the medicinal public in months of the drug's endorsement in late March 1998. Meanwhile formerly, the FDA has complete obtainable information on deaths in patients receiving sildenafil among the period of its endorsement and mid-November 1998 [57].Besides, PDE5 is not present in cardiac myocytes, and sildenafil has been exposed to take no straight inotropic special effects on dog trabeculae muscle (Pfizer, unpublished data). Though, sildenafil has not been examined widely in heart failure patients [58].

\section{DISCUSSION}

Sildenafil is a sexual dysfunction and a psychotropic drug which is used in the form of antidepressants. This was a major essential growing problem that provides us to keep the use of sildenafil in differential for any patient who present with symptoms described about. Human health is directly affected by Neurological dysfunction. Some study also shown that the sildenafil uses in the sexual assault cases by giving the drug forcefully to the teenagers so, that they go in the unconscious 
state. This study shows that sildenafil, directed in particular oral dosages, is in effect in improving erectile activity in patients with male erectile dysfunction for which there is no recognised biological cause. Due to the overdose of the sildenafil drug, the person occur various disease like strokes, heart failure and death may be also occur. The absence of scientific study in human awareness about the hazard of sildenafil and adolescence will unceasingly use and mainly by those who have already experienced the effect of sildenafil.

\section{CONCLUSION}

Sildenafil is an operational oral drug for erectile dysfunction. The toxicologist have detected the minor and major effects on various parts of the human body. Analytical techniques which is use to detect the concentration of the drug from the body are HPLC, spectrophotometer, GC-MS, LC-MS etc._Additional connected study decided out in the upcoming with sample confined in different conditions, will allow a quantitative report of the drug in these samples to be defined at the national level. The occurrence of contrary proceedings owed to sildenafil may be greater than primarily described.

\section{REFERENCES}

[1] Burls, A., Clarke, W., Gold, L., \& Simpson, S. (2001). Sildenafil: an oral drug for the treatment of male erectile dysfunction. BRITISH JOURNAL OF CLINICAL GOVERNANCE-BRADFORD-, 6(1), 55-56.

[2] Dunn, P. J., Galvin, S., \& Hettenbach, K. (2004). The development of an environmentally benign synthesis of sildenafil citrate (ViagraTM) and its assessment by Green Chemistry metrics. Green Chemistry, 6(1), 43-48.

[3] American Psychiatric Association. Diagnostic and statistical manual of mental disorders (Fourth edition; DSM-IV). Washington,DC: APA, 1994;

[4] Viagra (sildenafil citrate) package insert, Pfizer Inc.

[5] Boolell M, Allen MJ, Ballard SA, et al. Sildenafil: an orally active type 5 cyclic GMP specific phosphodiesterase inhibitor for the treatment of penile erectile dysfunction. Int $J$ Impot Res. 1996; 8:47-52.

[6] Uckert S, Kuthe A, Stief CG, et al. Phospho diesterase isoenzymes as pharmacological targets in the treatment of male erectile dysfunction. World J Urol. 2001; 19:14-22.

[7] Zusman RM, Prisant LM, Brown MJ. Effect of sildenafil citrate on blood pressure and heart rate in men with erectile dysfunction taking concomitant antihypertensive medications. $J$ Hypertens 2000; 18:1865-9.
[8] Kloner RA (2000). Cardiovascular risk and sildenafil. American Journal of Cardiology, 86: 57F-61F (4).

[9] Boolell M, Allen MJ, Ballard SA, Gepi-Attee S, Muirhead GJ, Naylor AM, et al. Sildenafil: an orally active type 5 cyclic GMP-specific phosphodiesterase inhibitor for the treatment of penile erectile dysfunction. Int $\mathbf{J}$ Impot Res 1996; 8:47-52.

[10] Donahue SP, Taylor RJ. Pupil-sparing third nerve palsy associated with sildenafil citrate (Viagra). Am J Ophthalmol 1998; 126:476-7.

[11] Cheitlin, M. D., Hutter, A. M., Brindis, R. G., Ganz, P., Kaul, S., Russell, R. O., \& Fisher, J. D. (1999). Use of sildenafil (Viagra) in patients with cardiovascular disease. Journal of the American College of Cardiology, 33(1), 273282.

[12] Phillips BG, Kato M, Pesek CA et al. Sympathetic activation by sildenafil. Circulation 2000; 102:3068-73.

[13] Oliver JJ, Bell K, Leckie SM, Webb DJ. Interaction between glyceryl trinitrate and sildenafil citrate (VIAGRA) may last less than $4 \mathrm{~h}$. To be presented at: World Congress of the International Society for Sexual and Impotence Research; September 22-26, 2002; Montreal, Canada.

[14] Herrmann, H. C., Chang, G., Klugherz, B. D., \& Mahoney, P. D. (2000). Hemodynamic effects of sildenafil in men with severe coronary artery disease. New England Journal of Medicine, 342(22), 1622-1626.

[15] Saenz de Tejada I, Goldstein I, Blanco R, Cohen RA, Krane RJ. Smooth muscle of the corpora cavernosae: role in penile erection. Surg Forum 1985; 36: 623-4 (7).

[16] Aboseif SR, Lue TF. Haemodynamics of penile erection. Urol Clin North Am 1988; 15: 1-7 (8).

[17] Pfizer Viagra (sildenafil citrate): Information for Health Professionals. Available at: http://www.viagra.com. Accessed March 15, 2000 (1).

[18] Goldstein I, Lue TF, Padma-Nathan H, et al, for the Sildenafil Study Group: Oral sildenafil in the treatment of erectile dysfunction. N Engl J Med 338: 1397-1404, 1998 (3).

[19] Morales A, Gingell C, Collins M, et al: Clinical safety of oral sildenafil citrate (Viagra) in the treatment of erectile dysfunction. Int $\mathrm{J}$ Impot Res 10: 69-74, 1998 (4).

[20] Umrani, D. N., \& Goyal, R. K. (1999). Pharmacology of sildenafil citrate. Indian journal of physiology and pharmacology, 43, 160-164.

[21] Fendrich, M.,Johnson ,T.(2005).Editors' introduction to this special issue on club drug epidemiology. Substance Use \& Misuse 40:1179-1184. 
[22] Maxwell, J. C. (2005). Party drugs: properties, prevalence, patterns, and problems. Substance Use \& Misuse 40:1203-1240.

[23] Degenhardt, L.,Copeland, J.,Dillon,P.(2005). Recent trends in the use of "clubdrugs": an Australian review. Substance Use \& Misuse 40:1241-1256.

[24] Schwartz RH, Miller NS. MDMA (ecstasy) and the rave: a review. Pediatrics 1997; 100:705708 (1).

[25] Aldridge J, Measham F. Sildanfil (Viagra) is used as a recreational drug in England. BMJ 1999; 318:669 (11).

[26] Henry JA, Jeffreys KJ, Dawling S. Toxicity and deaths from 3, 4- methylenedioxymethamphetamine ("Ecstasy"). Lancet 1992; 340:384- 387 (12).

[27] Henry J, Hill I. Fatal interaction between ritonavir and MDMA. Lancet 1998; 325:17511752 (13).

[28] Harrington R, Woodward J, Hooten T, et al. Life-threatening interactions between HIV-1 protease inhibitors and the illicit drugs MDMA and gamma-hydroxybutyrate. Arch Intern Med 1999; 159:2221-2224 (14).

[29] The National Drug Control Strategy: 2000 annual report. Washington, DC: Office of National Drug Control Policy, 2000 (4).

[30] Goldstein T, Feldmen R. Oral siidenafiJ for the treatment of erectile dysfunct.ion. $\mathrm{Dr} J$ Urol 1997; 80: 91.

[31] Cheitlin, M. D., Hutter, A. M., Brindis, R. G., Ganz, P., Kaul, S., Russell, R. O., \& Fisher, J. D. (1999). Use of sildenafil (Viagra) in patients with cardiovascular disease. Journal of the American College of Cardiology, 33(1), 273282.

[32] Terrett NK, Bell AS, Brown D, et al. A potent and selective inhibitor of type 5 cGMP phosphodiesterase with utility for the treatment of male erectile dysfunction. Bioorg Med Chem Lett 1996; $1819-24$.

[33] Klüver H, Bucy PC, Klüver H, Bucy PC. Preliminary analysis of functions of the temporal lobes in monkeys 1939. J Neuropsychiatry Clin Neurosci 1997; 9:606-20.

[34] Stewart-Bentley M, Gans D, Horton R: Regulation of gonadal function in uremia. Metabolism 23: 1065-1072, 1974.

[35] Vobig MA, Klotz T, Staak M, et al. Retinal side effects of sildenafil. Lancet 1999; 353:375 (5).

[36] Marmor MF. Sildenafil (Viagra) and ophthalmology. Arch Ophthalmol 1999; 117; 518 (6).

[37] Laties A, Sharlip I. Ocular safety in patients using sildenafil citrate therapy for erectile dysfunction. J Sex Med 2006; 3: 12-27 (5).
[38] Neves G, Lagnado L. The retina. Curr Biol 1999; 9: R674-R677.

[39] Trexler EB, Li W, Massey SC. Simultaneous contribution of two rod pathways to All amacrine and cone bipolar cell light responses. J Neurophysiol 2005; 93: 1476-1485.

[40] Dacey DM, Liao HW, Peterson BB, Robinson FR, Smith VC, Pokorny J et al. Melanopsinexpressing ganglion cells in primate retina signal colour and irradiance and project to the LGN. Nature 2005; 17: 749-754.

[41] Nirenberg S, Carcieri SM, Jacobs AL, Lathman PE. Retinal ganglion cells act largely as independent encoders. Nature 2001; 411: 698-701.

[42] Runo JR, Loyd JE. Primary pulmonary hypertension. Lancet 2003; 361: 1533-1544.

[43] Rodriguez-Roisin R, Krowka MJ, Herve ' P, Fallon MB, on behalf of the ERS Task Force Pulmonary-Hepatic Vascular Disorders (PHD) Scientific Committee. Pulmonary Hepatic vascular Disorders (PHD). Eur Respir J 2004; 24: 861-880 (1).

[44] Ghofrani HA, Wiedemann R, Rose F, Schermuly RT, Olschewski H, Weissmann N, Gunther A, Walmrath D, Seeger W, Grimminger F. Sildenafil for treatment of lung fibrosis and pulmonary hypertension: a randomised controlled trial. Lancet 2002; 360:895-900 (17).

[45] Ghofrani HA, Reichenberger F, Kohstall MG, Mrosek EH, Seeger T, Olschewski H, Seeger W, Grimminger F. Sildenafil increased exercise capacity during hypoxia at low altitudes and at Mount Everest base camp: a randomized, double-blind, placebo-controlled crossover trial. Ann Intern Med 2004; 141:169-177 (14).

[46] Michelakis ED, Tymchak W, Noga M, Webster L, Wu XC, Lien D, Wang SH, Modry D, Archer SL. Long-term treatment with oral sildenafil is safe and improves functional capacity and hemodynamics in patients with pulmonary arterial hypertension. Circulation 2003; 108:2066-2069 (15).

[47] Ghofrani HA, Schermuly RT, Rose F, Wiedemann R, Kohstall MG, Kreckel A, Olschewski H, Weissmann N, Enke B, Ghofrani $\mathrm{S}$, et al. Sildenafil for long-term treatment of nonoperable chronic thromboembolic pulmonary hypertension. Am J Respir Crit Care Med 2003; 167: 1139-1141 (18).

[48] Hoeper MM,FaulenbachC, GolponH, WinklerJ, WelteT, Niedermeyer J. Combination therapy with bosentan and sildenafil in idiopathic pulmonary arterial hypertension. Eur Respir J 2004; 24:1007-1010.

[49] Oelz O, Ritter M, Jenni R, Maggiorini M, Waber U, Vock P, Bärtsch P. Nifedipine for high altitude pulmonary edema. Lancet 1989; 8674:1241- 1244 (6). 
[50] Bärtsch P, Maggiorini M, Ritter M, Noti C, Vock P, Oelz O. Prevention of high-altitude pulmonary edema by nifedipine. N Engl J Med 1991; 325:1284-1289 (7).

[51] Ghofrani HA, Rose F, Schermuly RT, et al. Oral sildenafil as long-term adjunct therapy to inhaled iloprost in severe pulmonary arterial hypertension. J Am Coll Cardiol 2003; 42: 158-164 (15).

[52] Hoeper MM, Taha N, Bekjarova A, Gatzke R, Spiekerkoetter E. Bosentan treatment in patients with primary pulmonary hypertension receiving nonparenteral prostanoids. Eur Respir J 2003; 22: 330-334 (16).

[53] Sastry BK, Narasimhan C, Reddy NK et al. A study of clinical efficacy of sildenafil in patients with primary pulmonary hypertension. Indian Heart J 2002; 54: 410-4.

[54] Sastry BK, Narasimhan C, Reddy NK et al. Clinical efficacy of sildenafil in primary pulmonary hypertension: a randomized, placebo-controlled, double-blind, crossover study. J Am Coll Cardiol 2004; 43: 1149-53.

[55] Hatzichristou, D. G. (2002). Sildenafil citrate: lessons learned from 3 years of clinical experience. International journal of impotence research, 14(S1), S43.

[56] Wallis RM. The pharmacology of sildenafil, a novel and selective inhibitor of phosphodiesterase (PDE) type 5. Nippon Yakurigaku Zasshi 1999; 114(Suppl 1):22P26P (21).

[57] Food and Drug Administration. Summary of reports of death in Viagra users received from marketing (late March) through mid-November 1988. FDA website: www.FDA.gov.

[58] Cheitlin, M. D., Hutter, A. M., Brindis, R. G., Ganz, P., Kaul, S., Russell, R. O., \& Fisher, J. D. (1999). Use of sildenafil (Viagra) in patients with cardiovascular disease. Journal of the American College of Cardiology, 33(1), 273282.

Citation: Rohit Kumar Verma, Mahipal Singh Sankhla, Rajeev Kumar. Toxic Effects of Sexual Drug Overdose: Sildenafil (Viagra). ARC Journal of Forensic Science. 2019 4(1): 26-31. http://dx.doi.org/10. 20431/2456-0049.0401003

Copyright: (C) 2019 Authors. This is an open-access article distributed under the terms of the Creative Commons Attribution License, which permits unrestricted use, distribution, and reproduction in any medium, provided the original author and source are credited. 